\title{
LIFI TECH FOR SCUBA DRIVER COMMUNICATION UNDER WATER
}

\author{
Ajoy Kumar \\ B. Tech student, Department of computer science and engineering \\ Ram Krishna Mahato Government Engineering College, \\ Purulia, West Bengal, India
}

\begin{abstract}
Scuba driver face a great challenge in the field of communication under water. For the communication purpose, they use hand signal or hand sign which is very difficult to understand and having life risk. To get rid of this Problem, we should use LIFI (Light Fidelity) technology. LIFI use light waves for the communication purpose and under water it can be used. We try to use lifi here for the communication between scuba drivers. Scuba driver already bring light with them and we use that light only to send voice message to the other scuba. We use a microphone which capture voice from the scuba and the light waves deliver this message to the nearby scuba. It is quite helpful for the scuba communication.
\end{abstract}

Key word: LIFI (Light Fidelity)

\section{INTRODUCTION}

Today we can't imagine a world without internet, wifi etc. Internet, wifi all these makes our life easier. We can send a text, voice and even video message in a few second to who sit at thousand miles far.

Then in 2011, Harald Hass discovered lifi (light fidelity). In his TED talk he explain and demonstrated all about the lifi, it actually work with light waves just like the wifi technology work with radio waves.

In simple language data can be send through the light signal.

But still now Scuba driver use hand signal to communicate each other under water because wifi that means radio waves or signal is not working under water. But now no more hand signal, we can use lifi technology. lifi send data or information as the speed of light for that it is quite useful.

\section{EXISTING SYSTEM}

Our first stage of communication revolution starts with the hand sign. And now we can't think a world without internet, wifi etc.

But even now today's technology fails in communicating under water for scuba driver. We have no such method or technology which can help us in this problem.
The only method we use to communicate is hand sign. It is the only method through they can understand one another.

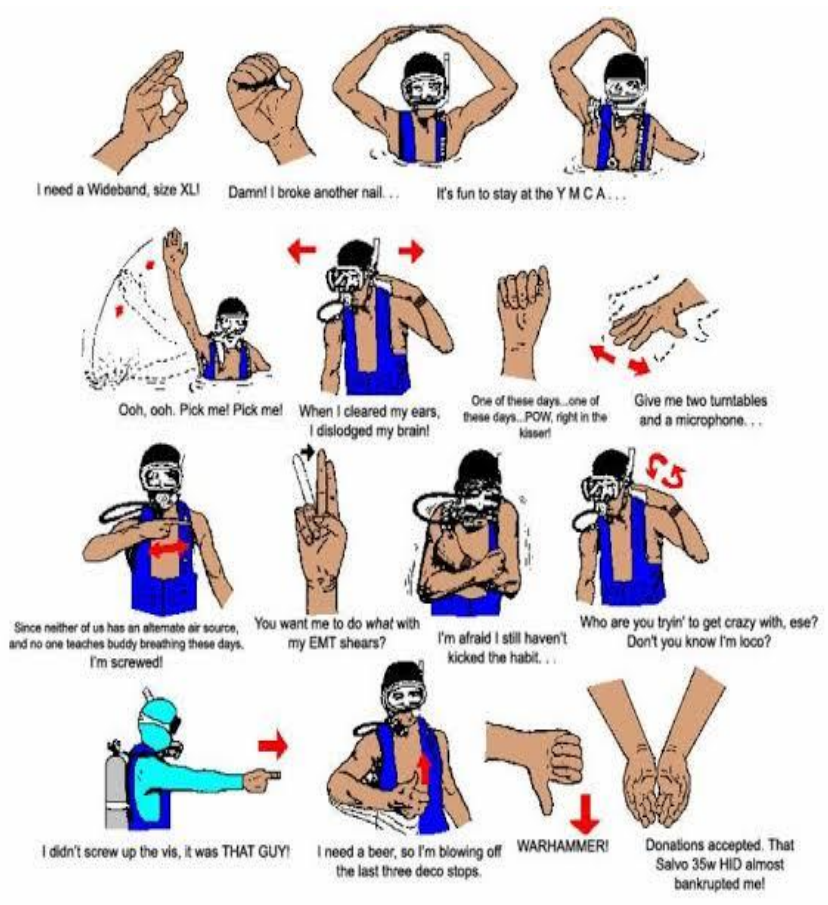

Fig.1

All above hand signals are used by scuba.

\section{PROBLEM WITH THE EXISTING SYSYTEM}

Now we discuss all the problem faced by scuba driver with the existing system that is communication through hand sign.

1. During night diving Scuba have to face difficult to understand the hand sign due to absence of light.

Fig. 2 explain the problem properly 


\section{International Journal of Engineering Applied Sciences and Technology, 2019 \\ Vol. 4, Issue 8, ISSN No. 2455-2143, Pages 144-147 \\ Published Online December 2019 in IJEAST (http://www.ijeast.com)}

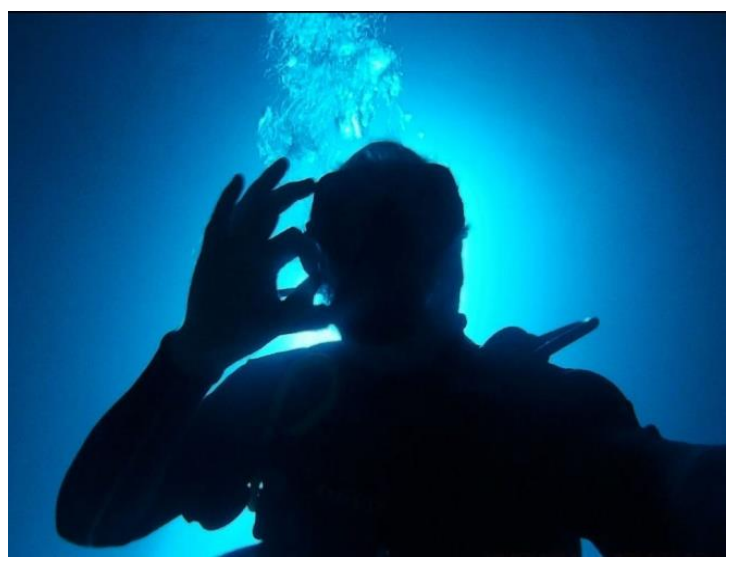

Fig. 2

2. Scuba driver have to face the same problem where sunlight can't penetrate through water.

Fig no: 03 explain the problem properly

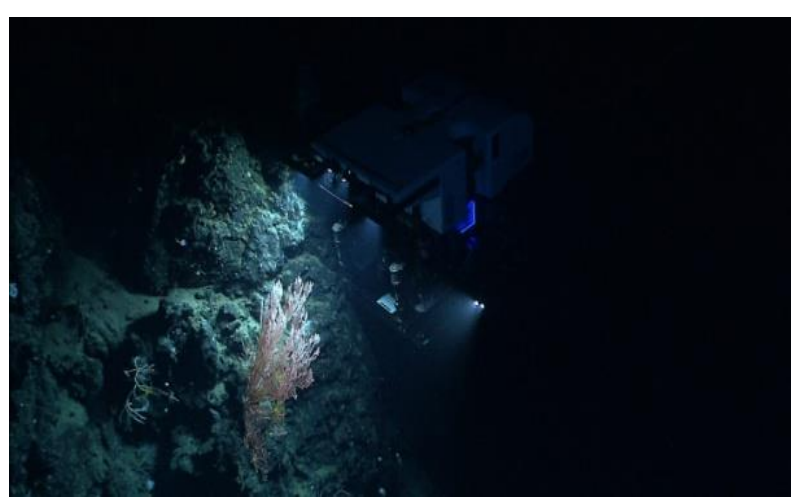

Fig. 3

3. Scuba driver have to bring limited oxygen with them and this communication method take much time to understand the other scuba.

4. Those entire problems increase the life risk of a scuba driver.

\section{Proposed System}

In proposed system we will use lifi technology in place of hand sign.

Which allow the scuba to communicate with other scuba with Voice.

The main problem I faced to establish this proposed system is about a matter that scuba can't talk under water because an oxygen mask is attached with their mouth.

Fig. 4 explain it.

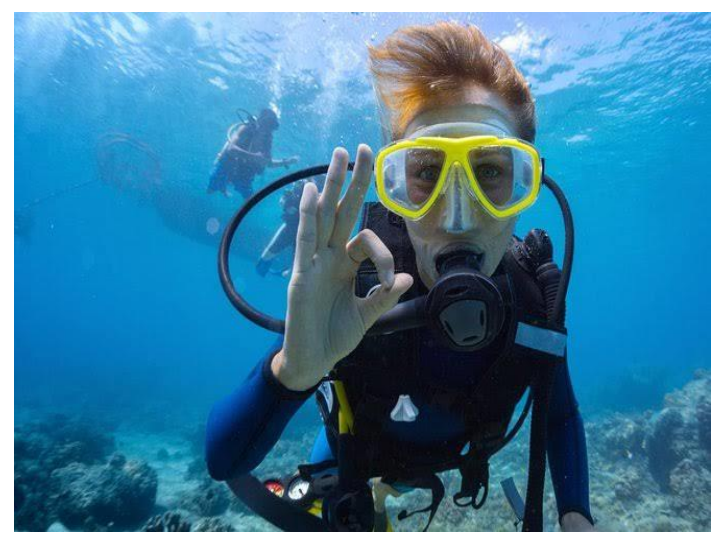

Fig. 4

But to get rid of this problem we have to use a scuba helmet which allows them to breath under water.

But now many companies develop such scuba helmet which allows them to breathe inside water freely.
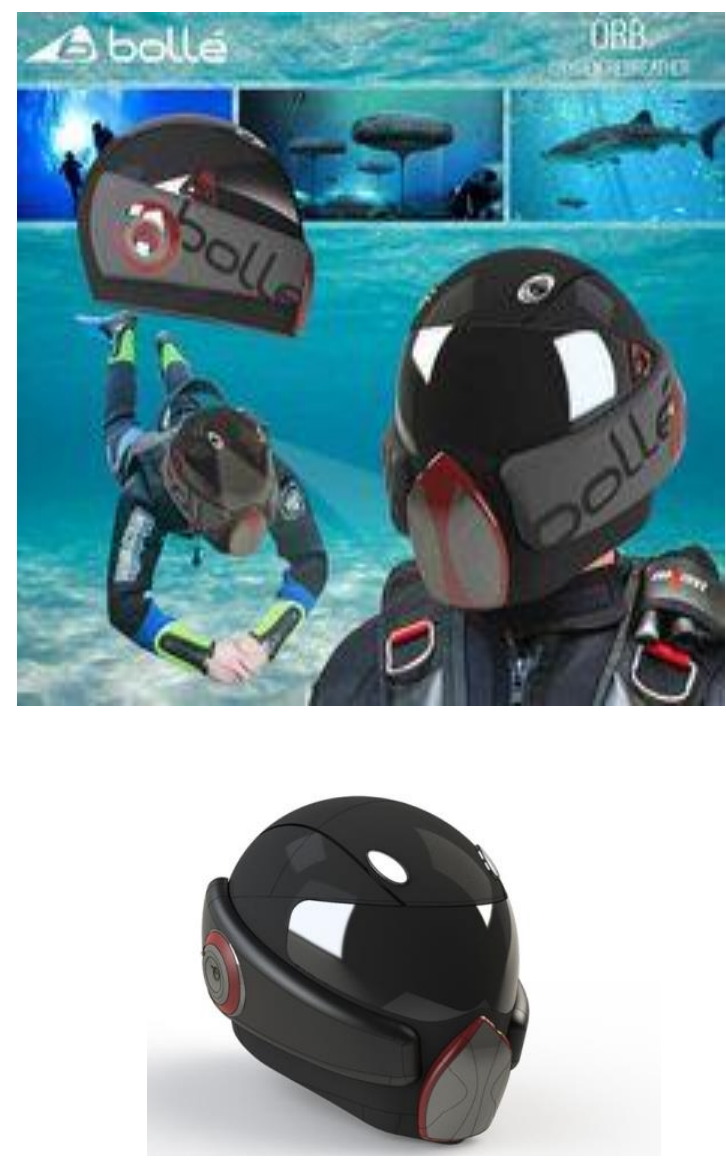

This is the scuba helmet which allow them to breath inside their helmet.

Here we use such type of scuba helmet for lifi communication. 


\section{International Journal of Engineering Applied Sciences and Technology, 2019 \\ Vol. 4, Issue 8, ISSN No. 2455-2143, Pages 144-147 \\ Published Online December 2019 in IJEAST (http://www.ijeast.com)}

\section{Architecture of proposed system}

Here we have to use such scuba helmet which allows us to breathe freely inside water it means we can also talk inside our scuba helmet.

Now we use this concept to develop our proposed system like that below.

\section{$\underline{\text { Transmitter scuba }}$}

We will connect a microphone with a circuit inside our scuba helmet.

Here is the circuit diagram

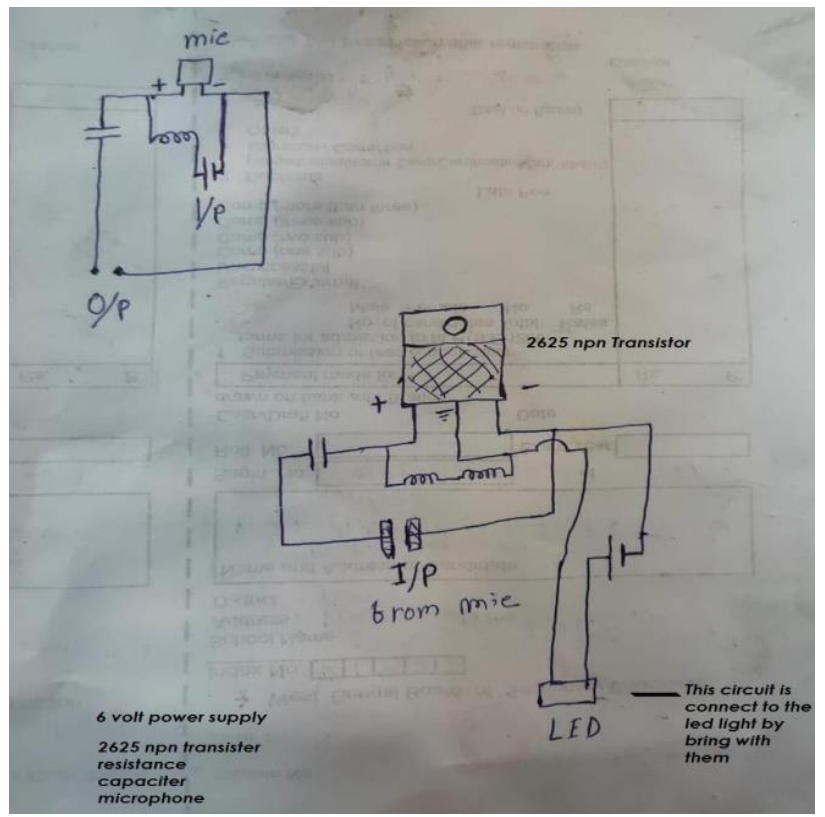

When scuba say something for the other scuba like move forward, wait etc inside the helmet then the microphone absorb this voice and then we will transfer this voice message to the other scuba through the light they bring during diving. Actually we will connect that microphone circuit with the light and for that the voice message gets converted into light waves.

\section{$\underline{\text { Receiver scuba }}$}

The other scuba driver will be the receiver scuba with respect to the first scuba.

We will connect this following circuit with a headphone and receiver for the receiver scuba inside its helmet.

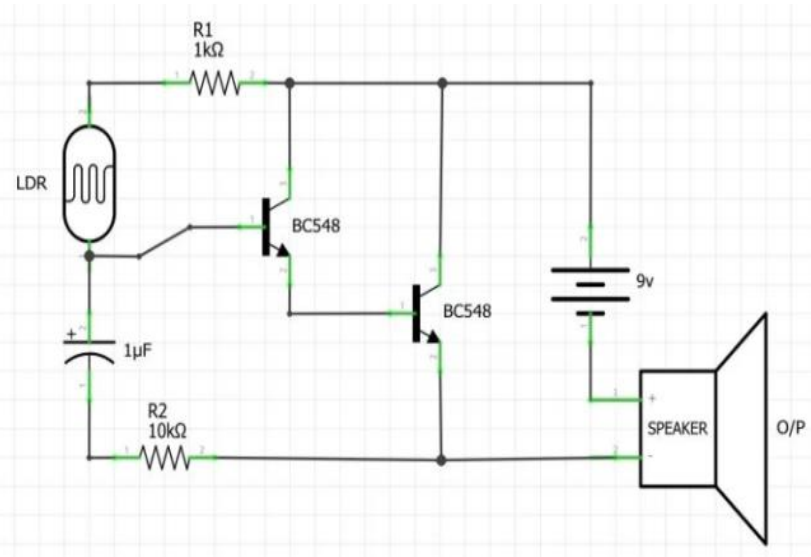

To receive the light waves we can use LDR or SOLAR PANEL as a receiver.
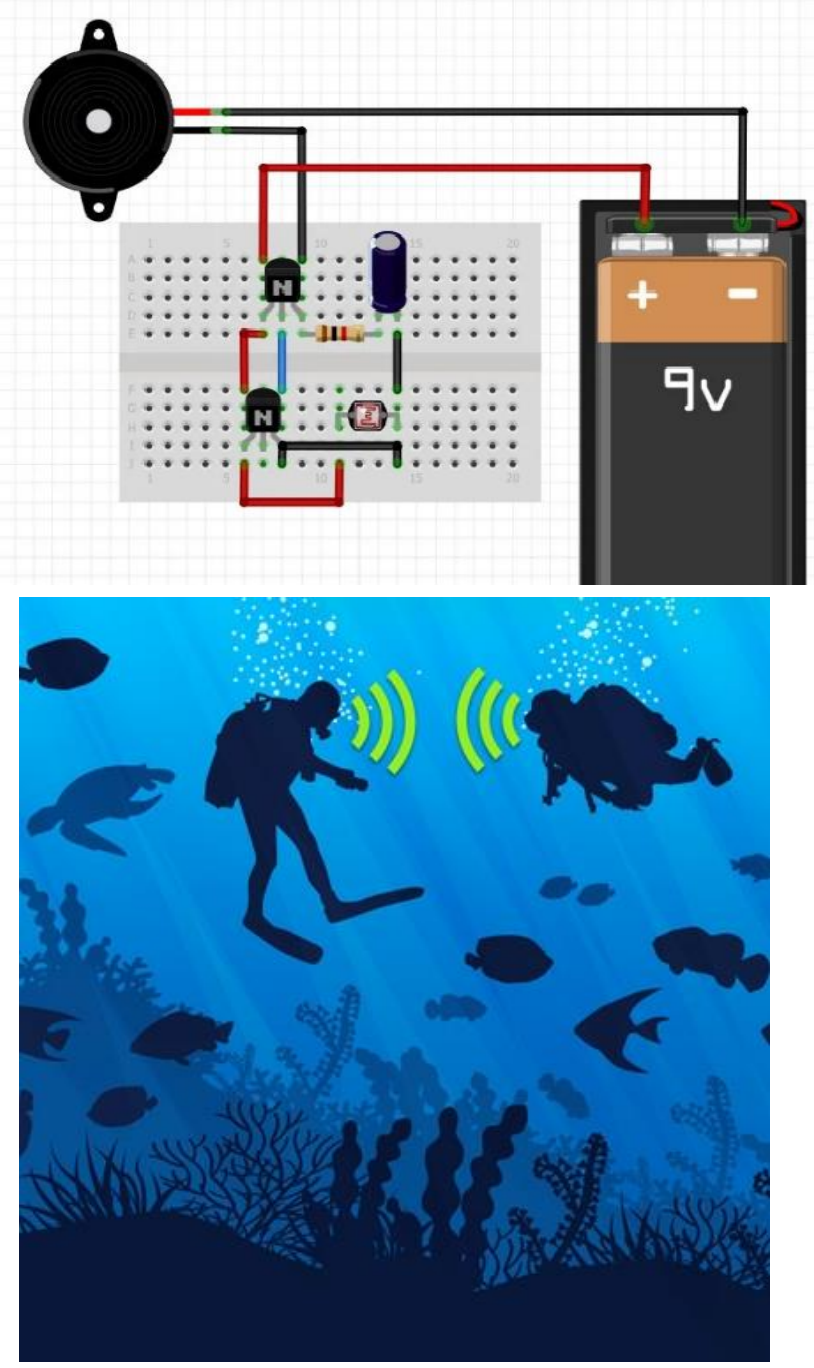


\section{International Journal of Engineering Applied Sciences and Technology, 2019 \\ Vol. 4, Issue 8, ISSN No. 2455-2143, Pages 144-147 \\ Published Online December 2019 in IJEAST (http://www.ijeast.com)}

The above fig properly explains how scuba will

communicate through lifi technology

\section{CONCLUSION}

Here lifi play its core role to improve the performance of scuba communication method. Lifi allow the scuba driver to send them voice message and for that it also decrease the life risk of scuba during diving.

\section{ACKNOWLEDGEMENT}

I thank my faculties and my superior tutors for their grateful help over making this paper.

\section{REFERENCES}

1. https://en.wikipedia.org/wiki/Li-Fi

2. https://www.leisurepro.com/blog/scubaguides/underwater-communication-for-scuba-divers/

3. https://www.divein.com/articles/orb-dive-helmet-isthis-the-future-of-scuba/

4. http://www.tuvie.com/futuristic-orb-scuba-divinghelmet-allows-you-to-breath-underwater-withoutheavy-equipment/

5. http://www.warse.org/pdfs/2014/icetetssp25.pdf

6. http://onlinejournal.in/IJIR V216/006.pdf

7. www.oledcomm.com

8. https://www.ijarcsse.com/docs/papers/volume_5/6 june2015/v516-0175.pdf

9. http://www.ijsrp.org/research-paper-0416/ijsrpp5275.pdf

10. http://www.ijarcase.com/dos/papers/volume 3/11_N ovember2013/V3I11-0434.pdf

11. W.-L Jin,"SPIVC:A Smartphone_ based inter _vehicle communication system," Proceedings of Transportation Research Board Annual Meeting,2012.

12. N. M. Husain Fidvi, "Car to Car Communication System," source: car communication system.

13. M. A. Chancey,"Short range underwater optical communication links,"Master's thesis, North Carolina State University

14. "Underwater Optical Wireless Communication ,'Hemani Kaushal,(member of IEEE), Georges Kaddoum (member of IEEE) dept of Electronics Communication and Engineering, NorthCap university, Gurgaon India. 